ISSN 1112-9867

http://www.jfas.info

\title{
THE DYNAMIC RELATIONSHIP BETWEEN SELECTED ASEAN STOCK MARKETS AND THEIR MACROECONOMIC VARIABLES
}

\author{
M. T. Ismail ${ }^{1 *}$, F. Z. Che Rose ${ }^{2}$, and A. R. Rosmanjawati ${ }^{1}$ \\ ${ }^{1}$ School of Mathematical Sciences, Universiti Sains Malaysia, Penang, Malaysia \\ ${ }^{2}$ Faculty of Integrative Sciences and Technology,Quest International University, Perak, \\ Malaysia
}

Published online: 17 October 2017

\begin{abstract}
This study investigates and analyzes the long run and short run relationships between selected ASEAN stock market indices and selected macroeconomic variables in a VAR framework. The ASEAN countries involved in this study are Indonesia, Malaysia, Philippines, Singapore and Thailand. The use of Johansen-Juselius Cointegration and Vector Error Correction Model (VECM) technique indicate that there are long run relationships between selected macroeconomic variables and stock market index in each of the ASEAN countries. Meanwhile, the Granger causality test indicates the existence of short run relationships between selected macroeconomic variables and stock market index. This study also shows that after a year the fluctuation of all the stock markets are caused by their own shocks.
\end{abstract}

Keywords: macroeconomic variables; VEC model; Granger Causality; forecast error variance decomposition (FEVD).

Author Correspondence, e-mail: m.tahir@usm.my

doi: http://dx.doi.org/10.4314/jfas.v9i5s.62 


\section{INTRODUCTION}

There is no doubt that stock markets are a part of the financial system which determine the economic growth and development in a country. Typically, positive economic growth portrayed that the economy performs well. If the economy performs well, the stock market is likely to do the same in terms of returns [1]. Therefore, the question of what determines the movement of stock markets becomes important. Nowadays, the theory that macroeconomic variables influences the movement of the stock market have been accepted. For many years, there are numerous studies have been focused on the relationship between macroeconomic variables and stock market movements. Initially, most of the studies are based on economic and financial theories. For example, studies based on quantity theory of money [2], capital asset pricing model [3], and arbitrage pricing theory [4].

Stock markets also has played an important role to assist economic growth by boosting liquidity and providing funds for various sectors. To be crystal clear, liquidity is defined as the ease and speed at which agents can buy and sell the asset or securities. [5] measure the stock market liquidity in two ways. First, they compute the ratio of total value traded to GDP. Second, they calculate the ratio of value traded divided by market capitalization or normally called turnover ratio. The stock prices are volatile and responds quickly to any domestic or international economic news.

Basically, the stock prices are determined by demand and supply from investors. Normally, the collapse of stock market tends to trigger a financial crisis and drive the economy into recession. The fluctuations of stock prices are based on many factors and there is no specific method to predict the movement of stock prices precise and persistently. [6] state that stock market is affected by many highly interrelated economic, social, political factors and they are interacting with each other in a complicated manner. Thus, the knowledge of relationship between stock market and macroeconomic variables is important to investors for them to allocate the capital and diversify their portfolio efficiently. Similarly, it will help policymakers broaden the investor base and range of financial products to boost the domestic capital market.

In this paper the main objective is clearly demarcate the short run and the long run equilibrium relationship between ASEAN-5 stock markets and selected macroeconomic variables. However, the approach for macroeconomic variable selection are done using a statistical method where 
previous studies have not exposed why and how the macroeconomic variables were selected. Moreover, the study also expands previous work by forecasting the fluctuations of ASEAN-5 stock indices due to its own shocks and also from other macroeconomic variables.

The rest of this paper is structured as follows. Section 2 reviews the literature. Section 3 sheds light on definitions of variables and methodology that were used in this paper. Section 4 discusses the empirical results. Finally, conclusions and recommendations are presented in the last section.

\section{LITERATURE REVIEW}

At early stage, Arbitrage Pricing Theory (APT) model was developed to elaborate which multiple factors can be used to explain the returns on financial asset [4]. However, the model was criticized due to failure in identifying the exact factors to explain the returns on financial asset. [7] employed APT model to further analyze that economic variables have a systematic effect on the stock market returns. Besides, they also linked a linear function to various macroeconomic factors to the returns on financial asset. However, the use of regression with ordinary least square estimation method tends to yield misleading outcomes. Thus, [8] and [9] developed a concept of cointegration that could be applied to analyze the long run equilibrium relationship. Nowadays, cointegration test have been widely used to analyze the relationship between stock markets and macroeconomic variables such as in [10][11][12] [13][14] [15].

The importance of stock market growth as indicator to the economic growth of any country is undeniable. The fluctuations of stock markets are caused by many factors but there is no specific method to predict the movement of stock prices precise and persistently. [6] states that stock market is affected by many highly interrelated economic, social, political factors and they interact with each other in a complicated manner. Numerous studies has been conducted to investigate which macroeconomic variables show significant dynamic linkages to stock market, and there are many have been well documented such as in $[10][13][14][16][17]$.

A study by [18] have been done to look into the impact of macroeconomic factors on the stock market of Estonia. The study applied the GARCH model in the empirical work to produce consistent and unbiased estimates and found that the Estonian stock market has a positive relationship to the debt/GDP ratio, real GDP and German stock index. Meanwhile, 
[19] studied the impact of variables such as money supply, consumer price index, interest rate and industrial production index to the Stock Exchange of Thailand Index (SETi). Their findings reported that the selected macroeconomic variables and SETi are cointegrated at I(1) and have significant long run equilibrium relationship. Their finding also showed that money supply shows a positive relationship with SETi in the long run, whereas there are negative linkages between the consumer price index and industrial production index with the SETi. In addition, they also determined a bidirectional causality between money supply and industrial production index by utilizing Granger causality test.

Furthermore, [20] investigates the effects of macroeconomic variables and their role in the growth of stock markets in selected European countries. However, instead of time series data, they used a dynamic panel data. The study found that income, monetization ratio, liquidity ratio, saving rate and inflation significantly affect the stock market growth. As addition, the study also found the negative impact of monetization ratio and inflation on the stock market growth whereby in the other hand there is a negative impact of income, liquidity ratio, saving rate on stock market growth.

Meanwhile, [21] examines the causality effect between the volatilities of exchange rate and stock market prices in Pakistan by using monthly time series data of Karachi Stock Exchange prices (KSE-100 Index). The results show a bidirectional relationship between the exchange rate volatility and the stock market prices in Pakistan. Recent study by [22] found that there is a long-term relationship between the exchange rate, 10 years long-term bond rate, the consumer price index and the Brent oil price with the stock market of Kazakhstan. Last but not least, a comprehensive review of literatures based on the existing theoretical and empirical studies on the determinants of stock market development can be found in [23].

From the above mentioned of previous studies there are no clues at all on why and how the macroeconomic variables were selected. Rather than randomly selects the macroeconomic variables, this study employed multiple regression to determine the significant variables that are later will be used in VECM model. This study is keen to investigate the linkages between ASEAN-5 stock markets and the selected macroeconomic variables. Furthermore, this study also wish to examine how ASEAN-5 stock indices respond to changes in macroeconomic variables. However, this study only focuses on 5 ASEAN members, namely Indonesia, 
Malaysia, Philippines, Singapore and Thailand. The rest of ASEAN members were excluded due to limitation of data for the study period. Besides, this study is only focus on the selected most active stock index in the South East Asia region.

\section{METHODOLOGY AND DATA}

In this study, Multiple Regression is used to determine the significant variables to be estimated as the Vector Error Correction Model (VECM). Prior to that, a unit root test to determine stationarity of the variables and the Vector Autoregressive (VAR) model to seek the short run relationships between the selected variables. Besides, JuseliusCointegration (JJ) test and VECM model for finding long run relationship, Granger Causality test is applied to describe the causal effect between those variables. The last procedure in the analysis will be the Forecast Error Variance Decomposition (FEVD). All the methods involved in this study are elaborate in details in the following sections. The section end with the discussion of time series data used for each country.

\subsection{Multiple Regression}

Multiple regression model is used to describe the relationship between the dependent variable $y$ and the set of independent variables $x_{1}, x_{2}, \cdots, x_{k}$. In this paper, $y$ represents stock markets whereby $x$ represents macroeconomic variables. Therefore, the multiple regression model can be written as:

$$
y=\beta_{0}+\beta_{1} x_{1}+\cdots+\beta_{k} x_{k}+\varepsilon(1)
$$

The $\beta$ parameters in (1) are called regression coefficients and there needs to be estimated. In order to estimate the $\beta^{\prime} s$ in (1), a sample of n observations on $y$ and the associated $x$ variables. Therefore, the model for the $i$-th observation is

$$
y_{i}=\beta_{0}+\beta_{1} x_{i 1}+\cdots+\beta_{k} x_{i k}+\varepsilon_{i} ; i=1, \ldots, n
$$

In the other hand, the $n$ equations can be written in matrix form as

$$
\left(\begin{array}{l}
y_{1} \\
y_{2} \\
\vdots \\
y_{n}
\end{array}\right)=\left(\begin{array}{ccccc}
1 & x_{11} & x_{12} & \ldots & x_{1 k} \\
1 & x_{21} & x_{22} & \ldots & x_{2 k} \\
\vdots & \vdots & \vdots & & \vdots \\
1 & x_{n 1} & x_{n 2} & \ldots & x_{n k}
\end{array}\right)\left(\begin{array}{c}
\beta_{0} \\
\beta_{1} \\
\vdots \\
\beta_{k}
\end{array}\right)+\left(\begin{array}{c}
\varepsilon_{1} \\
\varepsilon_{2} \\
\vdots \\
\varepsilon_{n}
\end{array}\right) \text {, }
$$


or $\mathbf{y}=\mathbf{X} \boldsymbol{\beta}+\boldsymbol{\varepsilon}$, with assumptions that $E\left(\varepsilon_{i}\right)=0, \operatorname{Var}\left(\varepsilon_{i}\right)=\sigma^{2}$ for $i=1, \ldots, n$ and $\operatorname{cov}\left(\varepsilon_{i}, \varepsilon_{j}\right)=0$ for all $i \neq j$.

\subsection{Unit Root Test}

The unit root test is a test of non-stationary condition. It can be determined by either through simple observation of the plotted data or accurately by using statistical test procedures [24]. The non-stationary time series may lead to inaccurate regression, in which a model has higher R-squared but there is no meaningful relationship between the variables. This produces bias and wrong conclusion. Therefore, to avoid this problem, this study uses the Augmented Dickey-Fuller (ADF) and Phillips-Peron (PP) unit root tests in which, they allow the differentiation of the variable of interest until the stationary condition is achieved [25]. The hypothesis test for Augmented Dickey-Fuller (ADF) and Phillips-Peron (PP) unit root tests are the null hypothesis is series contain unit roots, and alternative hypothesis is series without unit roots.

\subsection{Vector Autoregressive (VAR) Model}

We begin with an autoregressive of order $\mathrm{p}, \mathrm{AR}(\mathrm{p})$ process, which can be written as

$$
y_{t}=\mu+\alpha_{1} y_{t-1}+\cdots+\alpha_{p} y_{p-1}+\varepsilon_{t}
$$

Now, consider a column vector of $\mathrm{k}$ different variables, $y_{t}=\left[y_{1 t}, y_{2 t}, \cdots, y_{k t}\right]^{\prime}$ and model this in term of past values of the vector. The result is a vector autoregressive or VAR. Thus, $\operatorname{VAR}(\mathrm{p})$ process is as

follows:

$$
y_{t}=\mu+A_{1} y_{t-1}+\cdots+A_{p} y_{p-1}+\varepsilon_{t},
$$

wherethe $A_{i} ; i=1, . ., p$ are $k \times k$ matrices of coefficients, $\mu$ is a $k \times 1$ vector of contants, and $\varepsilon_{t}$ is a vector of white noises with properties $E\left(\varepsilon_{t}\right)=0$ for all

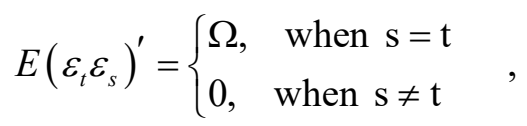

where the $\Omega$ is the covariance which is assumed to be positive definite. Thus, the $\varepsilon^{\prime} S$ areuncorrelated but may be contemporaneously correlated. 


\subsection{VAR Lag Length Selection}

This study refers to standard information criteria such as Akaike Information Criteria (AIC), and Final Prediction Error (FPE). Information criteria require no such normality assumptions concerning the distributions of the errors. Lag length of VAR is chosen in levels to minimize the information criterion. In multivariate case with $k$ variables and $T$ observations, a constant term and a maximal lag of $p$, these criteria are as follows:

$$
\begin{aligned}
& \operatorname{FPE}(p)=\left[\frac{T+k p+1}{T-k p-1}\right]^{k}\left|\sum_{\hat{\mu} \hat{\mu}} p\right| \\
& \operatorname{AIC}(p)=\ln \left|\sum_{\hat{\mu} \hat{\mu}} p\right|+\left(k+p k^{2}\right) \frac{2}{T}
\end{aligned}
$$

Note that $\left|\sum_{\hat{\mu} \hat{\mu}} p\right|$ is the determinant of the variance-covariance matrix of the estimated residuals.Using the same lag length, the number of cointegration exist is determine using Johansen - Juselius (JJ) test.

\subsection{Johansen-Juselius (JJ) Test}

Basically, if there exists a stationary linear combination of nonstationary random variables, the variables combined are said to be cointegrated. JJ test is a procedure to test the cointegrations of more than two variables used in the equation. Its procedure builds cointegrated variables directly on maximum likelihood estimation. Specifically, this test will determine the number of cointegration vector. When applying JJ test, we need to identify the number of lags in each cointegration and to choose the one seems more plausible from possible specifications in the test. Johansen procedure is to test the restriction imposed by cointegration on a vector autoregression (VAR) model in (3) where $y_{t}$ is a $k$-dimension vector of variables which are assumed to be $\mathrm{I}(1)$ series ( but can also be $\mathrm{I}(0)$ ) , $A i, i=1, \ldots$, is the coefficient matrix, and $\varepsilon_{t}$ is a $k$-dimension vector of residuals. Subtracting $y_{t-1}$ from both sides of equation (3) yields

$$
\Delta y_{t}=\mu+\Pi y_{t-1}+\Gamma_{1} \Delta y_{t-1}+\cdots+\Gamma_{p-1} \Delta y_{t-p+1}+\varepsilon_{t},
$$

where $\Pi=\sum_{i=1}^{p} A_{i}-1$ and $\Gamma_{i}=-\sum_{j=i+1}^{p} A_{j}$. Observe that only one term in the equation, $\Pi y_{t-1}$, is 
in levels. Cointegration depends crucially on the property of matrix $\Pi$. It is clear that $\Pi y_{t-1}$ must be either $\mathrm{I}(0)$ except that $y_{t}$ is already stationary. There are three situations:

i) $\Pi=\alpha \beta^{\prime} \quad$ has a reduced rank $0<r<k$;

ii) $\Pi=\alpha \beta^{\prime}$ has a rank of zero; and

iii) $\Pi=\alpha \beta^{\prime}$ has a full rank.

Under situation (i), $\alpha$ and $\beta$ are both $k \times r$ matrices and have a rank of $r$. There are $r$ cointegration vectors $\beta^{\prime} y_{t}$ which are stationary $\mathrm{I}(0)$. It is equivalent to having $r$ common trends among $y_{t}$. The stationarity of $\beta^{\prime} y_{t}$ implies a long-run relationship among $y_{t}$ or a subset of $y_{t}$ - the variables in the cointegration vectors will not depart from each other over time.

$\beta^{\prime} y_{t}$ are also error correction terms, where the departure of individual variables in the cointegration vectors from the equilibrium is subsequently reversed back to the equilibrium. This dynamic adjustment process is called error correction mechanism (ECM). Equation (4) is therefore called VAR with ECM. Under situation (ii), there is no cointegration equation relation among $y_{t}$ and the variables in levels do not enter equation (4) which simply become a VAR without ECM. Meanwhile, under situation (iii), the variables in levels are already stationary.

Besides, the common likelihood ratio test involves are trace and maximum eigenvalue test. For trace and maximum eigenvalue test statistics, the null hypothesis, $H_{0}$ is that there are $\mathrm{r}$ or fewer cointegration vectors, whereas the alternative hypotheses, $H_{1}$ are $r+1$ and at least $t+1$ cointegration vector for the maximum eigenvalue and trace statistics. Trace statistics can be expressed as

$$
\lambda_{\text {trace }}(r)=-T \sum_{i=r+1}^{n} \ln \left(1-\hat{\lambda}_{i}\right)
$$

On the other hand, maximum eigenvalue test can be expressed as 


$$
\lambda_{\max }(r, r+1)=-T \ln \left(1-\hat{\lambda}_{r+1}\right)
$$

The decision isbased on the following Table 1.

Table 1. Decision Based on trace and maximum eigenvalues test statistics

\begin{tabular}{llll}
\hline$H_{0}$ & $H_{1}$ & $\lambda_{\max }$ and $\lambda_{\text {trace }}$ value & Decision \\
\hline$r=0$ & $r>0$ & $\lambda_{\text {trace }} / \lambda_{\max }>$ critical value & Reject $H_{0}$ \\
$r \leq 1$ & $r>1$ & $\lambda_{\text {trace }} / \lambda_{\max }<$ critical value & Fail to reject $H_{0}$
\end{tabular}

According to [26], if the series are stationary after first differencing and they are cointegrated of order $r$, then $r$ number of error correction term(s) should be included in the VECM analysis.

\subsection{Vector Error Correction Model (VECM)}

For the short run analysis, the VECM technique test was employed to test the direction of Granger causality within the sample period. This method allows long-run components of variables to obey equilibrium constraints while short run components had a flexible dynamic specification. The general VECM can be written as:

$$
\Delta Y_{t}=\delta_{0}+\Pi Y_{t-1}+\sum_{i=1}^{m} \theta_{i} \Delta Y_{t-1}+\varpi_{t}
$$

where $Y_{t}$ is an $(n \times 1)$ vector of variables $y_{1}, y_{2}, \ldots, y_{n}, \delta_{0}$ is an $(n \times 1)$ vector of constants, $\Pi$ and $\theta$ are $(n \times n)$ matrices reflecting short run and long run effects, $\varpi t$ is a $(n \times 1)$ vector of white noise disturbances.

If variables in the system are not integrated, then $\Pi=0$ and the VECM is an unrestricted VAR. However if there is a cointegration relationship, the $\Pi$ can be decomposed into two ( $n$ x $r$ ) matrices of $\alpha$ and $\beta$, for example $\Pi=\alpha \beta^{\prime}$. For the error correction term, a general term is shown in equation (6).

$$
A(B)(1-B) y_{t}=-\varepsilon_{t-1}+d(B) \mu_{t}
$$

where $\mu_{t}$ is a stationary multivariate disturbance, with $\mathrm{A}(0)=\mathrm{I}, \mathrm{A}(1)$ has all the elements finite and $\alpha \neq 0$. This formula indicates the amount and direction of $\Delta Y_{t}$ in terms of size as well as sign of the previous equilibrium error, $\varepsilon_{t-1}$. If the coefficient of the error correction 
term(s) is statistically insignificant, then this variable does not deviate from the equilibrium. In short, the F-test of the explanatory variables indicates the short run causal relationship, while the t-test of the lagged error correction term(s) contains long run information.

\subsection{Granger Casualty Test}

In this study, Granger causality test is applied to explain the short-run relationship between macroeconomic variables and stock markets. The formal definition of Granger causality asks whether past values of $X$ aid in the prediction of $Y_{t}$, conditional on having already accounted for the effects on $Y_{t}$ of past values of $Y_{t}$ (and perhaps of past values of other variables). If they do, the $X$ is said to "Granger cause" $Y$. There are two directions of causality, firstly, unidirectional causality, in which when $Y_{t}$ causes $Y_{t}$ but not the other around. Secondly, bilateral causality, where when variables $X_{t}$ and $Y_{t}$ are jointly determined.

Following [8], the following equation (7) and (8), perform standard Granger Causality test with two variable $X_{t}$ and $Y_{t}$ of $\operatorname{VAR}(\mathrm{p})$ model.

$$
\begin{gathered}
Y_{t}=\alpha_{1}+\sum_{j=1}^{p} \alpha_{1 j} Y_{t-j}+\sum_{j=1}^{p} \beta_{1 j} Y_{t-j}+\varepsilon_{1 t} \\
X_{t}=\alpha_{2}+\sum_{j=1}^{p} \alpha_{2 j} X_{t-j}+\sum_{j=1}^{p} \beta_{2 j} X_{t-j}+\varepsilon_{2 t}
\end{gathered}
$$

There are three situations to be considered, and there are:

(i) If $\left\{\alpha_{11}, \alpha_{12}, \ldots, \alpha_{1 k}\right\} \neq 0$ and $\left\{\beta_{11}, \beta_{12}, \ldots, \beta_{1 k}\right\}=0$, there exist a unidirectional causality from $X_{t}$ to $Y_{t}$ denoted as $\mathrm{X} \rightarrow \mathrm{Y}$.

(ii) If $\left\{\alpha_{11}, \alpha_{12}, \ldots, \alpha_{1 k}\right\}=0$ and $\left\{\beta_{11}, \beta_{12}, \ldots, \beta_{1 k}\right\} \neq 0$, there exist a unidirectional causality from $Y_{t}$ to $X_{t}$, denoted as $\mathrm{Y} \rightarrow \mathrm{X}$.

(iii) If $\left\{\alpha_{11}, \alpha_{12}, \ldots, \alpha_{1 k}\right\} \neq 0$ and $\left\{\beta_{11}, \beta_{12}, \ldots, \beta_{1 k}\right\} \neq 0$, there exist a bilateral causality from $X_{t}$ and $Y_{t}$ denoted as $\mathrm{X} \leftrightarrow \mathrm{Y}$.

Meanwhile, the hypotheses in this test are as follows: 


\section{First hypothesis}

$H_{0}: \mathrm{X}$ does not Granger cause $\mathrm{Y}$ or $\left\{\beta_{11}, \beta_{12}, \ldots, \beta_{1 k}\right\}=0$, if $\mathrm{Fc}<$ critical value of $\mathrm{F}$.

$H_{1}: \mathrm{X}$ does Granger cause $\mathrm{Y}$ or $\left\{\alpha_{11}, \alpha_{12}, \ldots, \alpha_{1 k}\right\} \neq 0$, if $\mathrm{Fc}>$ critical value of $\mathrm{F}$

\section{Second hypothesis}

$H_{0}$ : Y does not Granger cause $\mathrm{X}$ or if $\mathrm{Fc}<$ critical value of $\mathrm{F}$.

$H_{1}$ : Y does Granger cause $\mathrm{X}$ or if $\mathrm{Fc}<$ critical value of $\mathrm{F}$.

\subsection{Forecast Error Variance Decomposition (FEVD)}

FEVD offer a slightly different method for examining VAR system dynamics. They give the proportion of the movements in the dependent variables that are due to their 'own' shocks, versus shocks to the other variables. A shock to the $i$ th variable will directly affect that variable of course, but it will also be transmitted to all the other variables in the system through dynamic structure of the VAR.

FEVD determine how much of the s-step-ahead forecast error variance of a given variable is explained by innovations to each explanatory variable. Suppose that we have observed the vectors $y_{1}, y_{2}, \ldots, y_{n}$. The minimum squared error forecast of $y_{n+1}$ is the conditional expectation of $y_{n+1}$ formed at time $n$ whichis

$$
\hat{y}_{n+1}=E\left(y_{n+1} \mid y_{1}, y_{2}, \ldots, y_{n}\right)=A y_{n}
$$

where $y_{n}$ denotes a forecast error. In general, the forecast involves equation (9) such that

$$
\hat{y}_{n+s}=A^{s} y_{n}+A^{s-1} \varepsilon_{n+1}+\ldots+\varepsilon_{n+s}+\varepsilon_{n+s}=A^{s} y_{n} .
$$

Meanwhile, the vector of forecast errors in the forecast for $s$ periods ahead is

$$
e_{s}=y_{n+s}-\hat{y}_{n+s}=\varepsilon_{n+s}+\varepsilon_{n+s}+\cdots+A^{s-1} \varepsilon_{n+1}
$$

with variance-covariance matrix for the forecast errors, $s$ periods ahead are

$$
\sum(s)=\Omega+A \Omega A^{\prime}+A^{2} \Omega\left(A^{\prime}\right)^{2}+\cdots+A^{s-1} \Omega\left(A^{\prime}\right)^{s-1}(11)
$$

where A is $k \times k$ matrices of coefficients and $\Omega$ is the covariance matrix that is assumed to be positive definite. In the transformations of $\varepsilon$ innovations to produce a new set of orthogonal innovations, there is Choleski factorization of the positive definite matrix $\hat{\Omega}$ 
which is written as

$$
\hat{\Omega}=P^{-1}\left(P^{-1}\right)^{\prime} .
$$

Thus, for forecast two or more periods ahead we return to the formula for the variance covariance matrix of forecast errors given in equation (11). Then, by substituting equation (12) into equation (11) we have

$$
\sum(s)=P^{-1}\left(P^{-1}\right)^{\prime}+P^{-1}\left(P^{-1}\right)^{\prime}+\cdots+\left(A^{s-1} P^{-1}\right)\left(A^{s-1} P^{-1}\right)^{\prime} .
$$

To some extent, impulses responses and FEVD offer very similar information.

\subsection{Data}

Association of Southeast Asian Nations (ASEAN) was established on 8 August 1967 currently contains ten member states. However, we limit this study to only five selected nations namely Indonesia, Malaysia, Philippines, Singapore and Thailand are investigated. The rest ASEAN members namely: Vietnam, Brunei Darussalam, Myanmar, Cambodia and Laos are excluded in this study due to unavailability of data for the study period. We employed Kuala Lumpur Composite Index (KLCI), Jakarta Composite Index (JCI), Philippines Stock Exchange Index (PSE), FTSE Straits Time Index (STI) and the Stock Exchange of Thailand (SET) to proxy for Indonesia, Malaysia, Philippines, Singapore and Thailand's stock market respectively. Besides, from previous studied we also employed ten selected macroeconomic variables for each nation. The ten variables are Consumer price index (CPI), Crude oil (OIL), Exchange rate (EXR), Gold prices (GOLD), Industrial production index (IPI), Interbank offer rate (IBOR), International reserves (INT RES), Money supply (M1 and M2) and Silver Prices (SILVER). The range of monthly stock market indices and macroeconomic variables involve were presented in Table 2.

Table 2. Length of time series data for each country

\begin{tabular}{ccc}
\hline Country & Length of Data & No. of Observations \\
\hline Indonesia & Jan 2001 - Nov 2014 & 167 \\
Malaysia & Jan 1998 - Nov 2014 & 203 \\
Philippines & Jan 1995 - Nov 2014 & 239 \\
Singapore & Jan 1995 - Nov 2014 & 239 \\
Thailand & Jan 1999 - Nov 2014 & 191 \\
\hline
\end{tabular}




\section{ANALYSIS AND RESULTS}

This section discusses further the analysis of time series data to investigate the long run and the short run relationship between ASEAN-5 stock indices and selected macroeconomic variables.The analysis start with time series plot, regression analysis, unit root test, Granger causality test and lastly forecast error variance decomposition (FEVD)

\subsection{Time Series Plot}

Time series plot is used to present the patterns and behavior of the time series data.Fig. 1 describes briefly the trending of JCI and macroeconomic variables in Indonesia. By looking closely at JCI plot, we found that the index point plunged about 1200 points in a period of five months starting from May 2008. The drops off in JCI happened may due to world the financial crisis had struck all over the world. The crisis initially triggered by the slowdown in the US economy cause by non-performing loans in the banking sector. To add fuel to the flame, American fourth largest investment bank, Lehmann Brothers collapsed due to bad return on investments. Besides, the fear that more banks could fail, causing investors and banks to take extreme precautions.

Generally, we found that all the stock prices show increasing trend with fluctuations over the years. Obviously by looking at KLCI in Fig. 2, there is plummeting in the stock market during the Asian financial crisis in 1997. The crisis started in Thailand with the financial collapse of the Thai baht caused by the decision of the Thai government to float the baht. As the crisis spread, most of South East Asia and Japan saw slumping currencies, devalued stock markets and other asset prices. This declining state occurs continuously until the end of 1999 and then the KLCI started to recover slowly. 

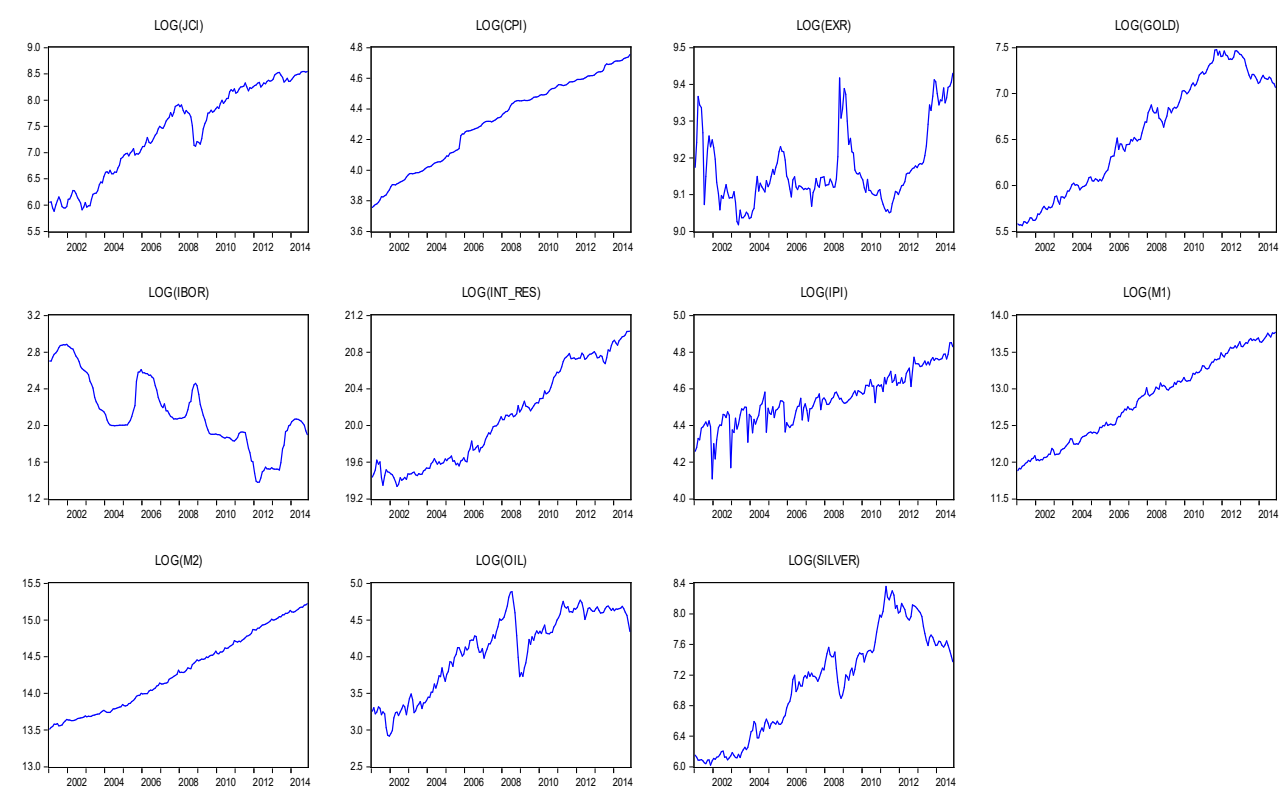

Fig.1.Times series plot of Indonesia
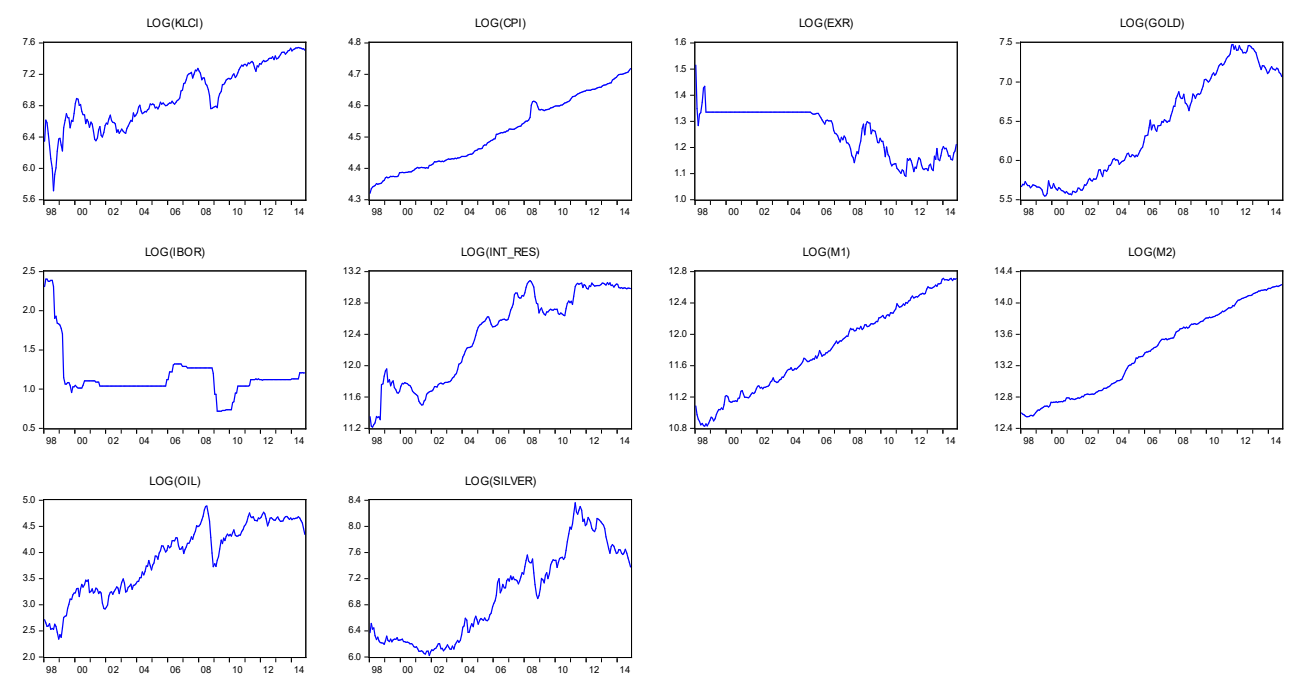

Fig.2. Times series plot of Malaysia

On the other hand, exchange rates in Malaysia depicted interesting trend where there is no fluctuation in foreign exchange rates for about 7 years. This is also due to the Asian financial crisis where Malaysian government led by Tun Dr. Mahathir Mohamad pegged Ringgit Malaysia with US dollar at RM 3.80/USD. This means that the exchange rate was no longer determined by demand and supply. This action was taken to curb inflation and temper interestrates, thus allowing for increased trade. 

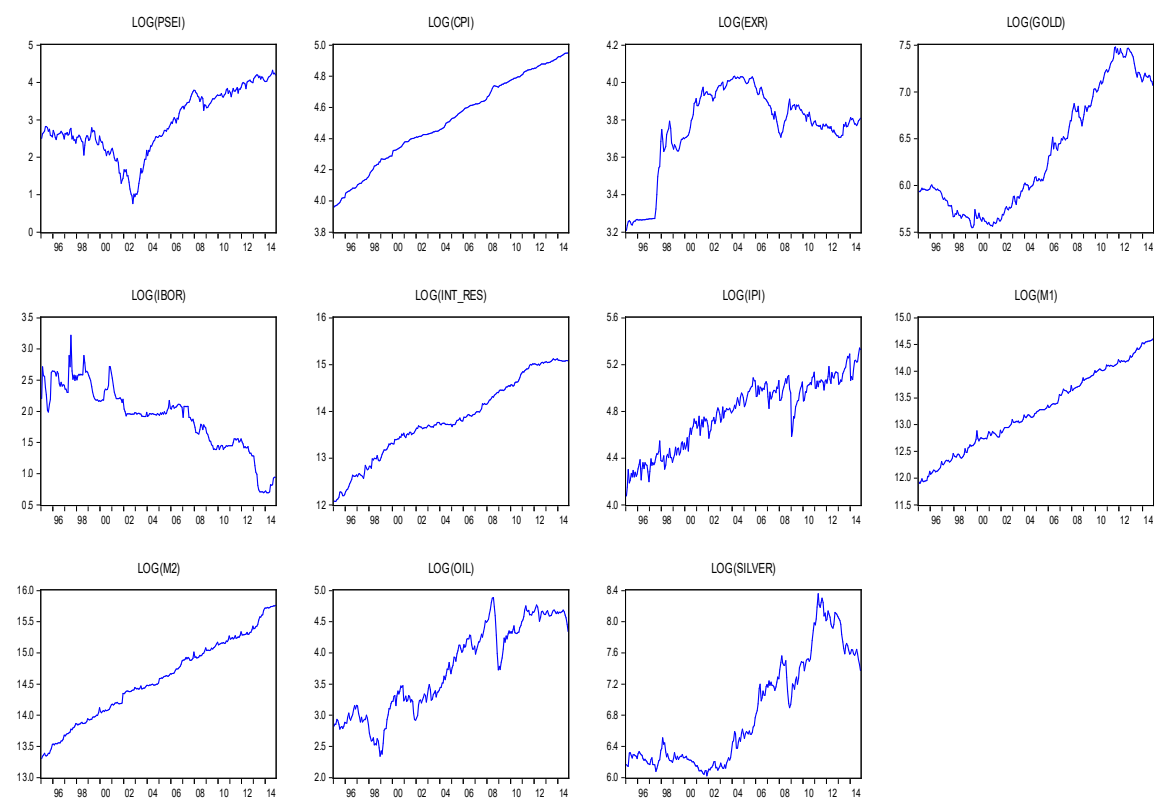

Fig.3. Times series plot of Philippines

Meanwhile, in the Philippines, CPI, INT RES, IPI, M1 and M2 shows steady increasing trend over the time. However, IPI show sudden drop about 11\% from October 2008 till January 2009. This may due to the world financial crisis that struck the manufacturing industries in Philippines. Besides, by looking closely on PSEi this study found that it falls to the lowest point in October 2002. Then, the index started to upsurge. Further interesting insight, the exchange rates of the Peso/US dollar has been escalated about 14\% from May 1997 until January 1998. The increasing trend clearly shows increasing of exchange rates in Philippines. This indicates that Peso has been weakened against greenback. Therefore, Filipinos need more Peso in exchange for one US dollar. The possible reason for this escalation may due to Asian Financial crisis during this period.

As expected the CPI, INT RES, IPI, M1 and M2 in Singapore depicted in Fig.3 shows steady upward trend over the time. Another interesting trend is a plunged of STI from 1629 to 856 points over 6 months period. The STI tumbled to its lowest point in August 1998 during the Asian financial crisis struck the ASEAN region. Then, the STI tumbled again in February 2009 to 1595 points. In general, this study found that the Singapore dollar is getting stronger as compared to US dollar. This can be seen in Fig. 4 where the exchange rates of Singapore show decreasing trend. As expected the CPI, INT RES, IPI, M1 and M2 in Singapore depicted in figure above shows steady upward trend over the time. 

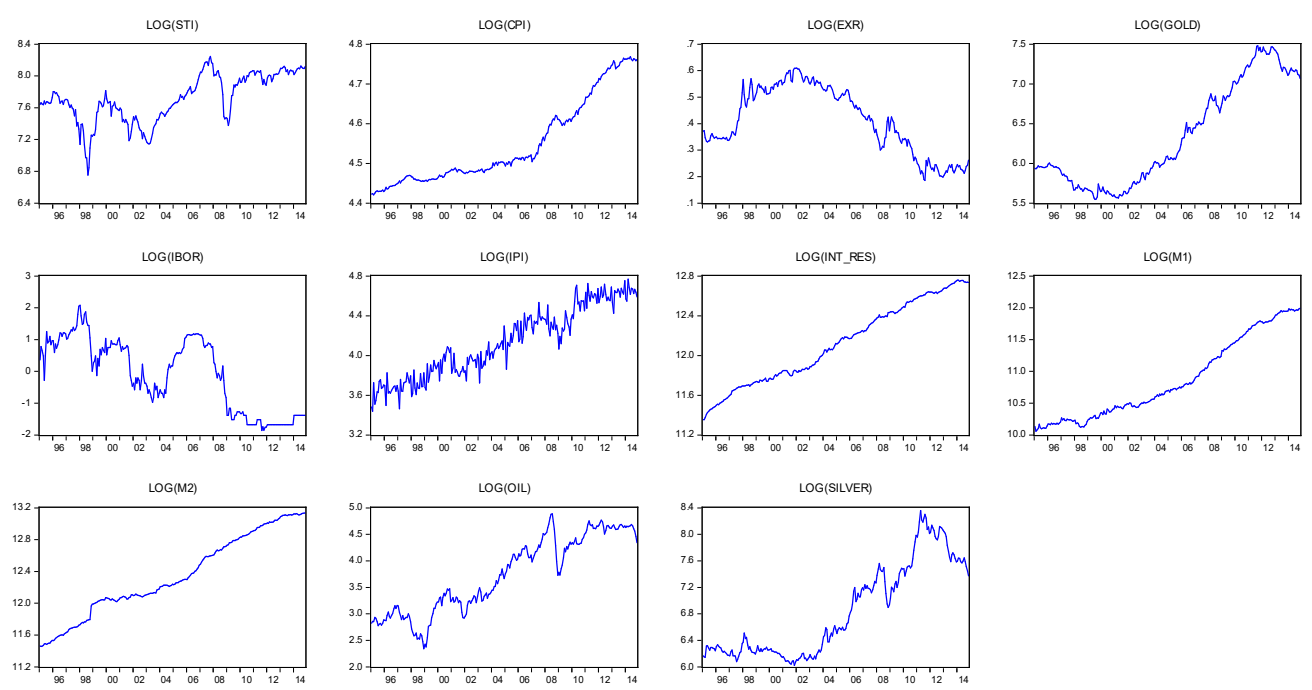

Fig.4. Times series plot of Singapore

Again, it is expected to see the SETi in Thailand tumbled about $50 \%$ to 402 points on November 2008. Then, the index soared indicating that Thailand's economy started to grow and recover from the crisis. Besides, from Figure 5 it is noted that there is about $50 \%$ sudden drop of IPI in 2011. This means that the industrial production had encountered a problem since the worst flood had struck Thailand and killed nearly 400 people. The floods have forced big industrial estates north of Bangkok to close, affected at least 9,859 factories and 660,000 jobs many other factories suspended their productions. The electronics and car sectors have suffered, Thailand is a regional hub for the world's top car producers, and even if most of the big assembly plants are in the east, away from the floods, car part firms have been hit [27]. Besides, over three quarters of Thailand's provinces were declared flood disaster zones, and the World Bank estimated that the economic loss exceeded 45 billion US dollars. By looking closely, we also found that there is a plunged of world crude oil price to its lowest price in 2009 at about 40 US dollars per barrel. 

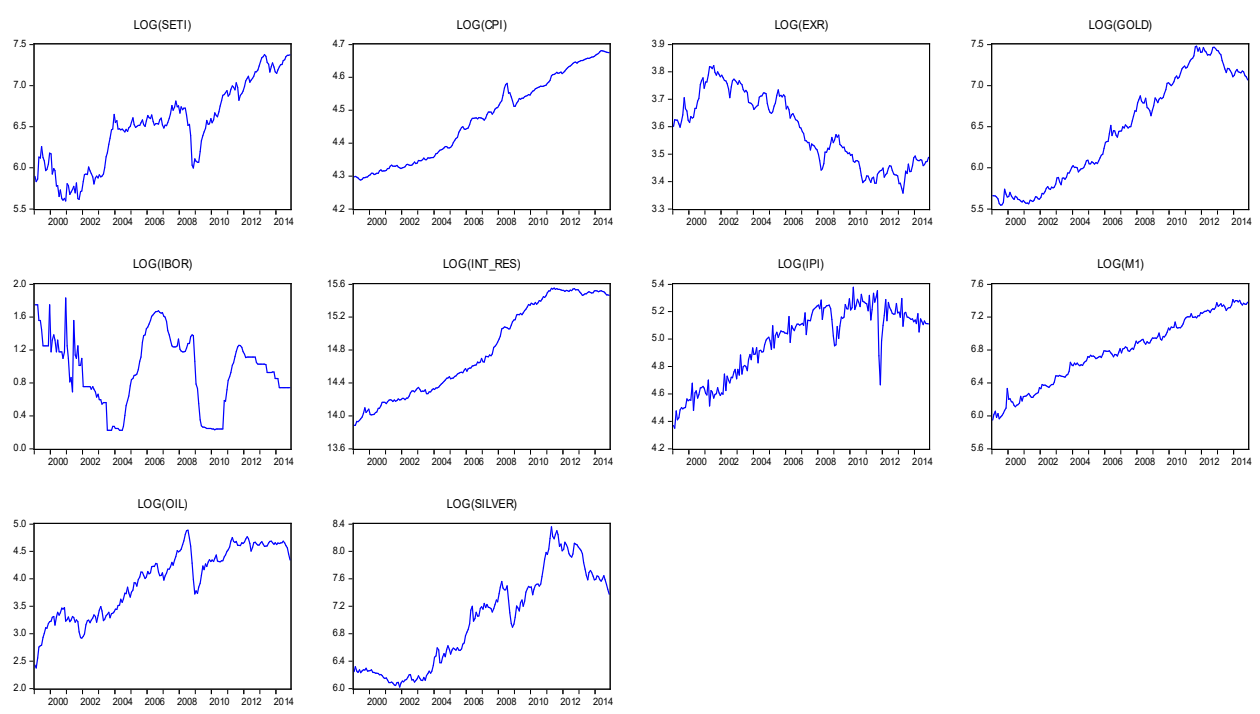

Fig.5. Times series plot of Thailand

\subsection{Regression Analysis}

Basically, the general purpose of regression analysis is to learn more about the relationship between one or several independent or predictor variables and a dependent or criterion variable. Conversely, this study adopted regression analysis to determine which predictor variables are significance to be used in modelling. Initially, ten predictors were chosen for each country (except Thailand without M2). Stock indices are defined as dependent variable while all the macroeconomic variables are defined as the predictors. Elimination of predictors will be done after multiple regression analysis results are obtained. Any variables that are significant at the $5 \%$ level will be chosen and used in the next steps.

Table 3simplifies the results of multiple regression by showing the coefficient of significant variables only. Note that, the grey-blank spaces are eliminated variables which are not statistically significant at the 5\% level. R-square values describe the amount of variation in the observed response values that is explained by the predictors. Thus, the R-square values in the Table 7 above indicates that macroeconomic variables used in this study can explain more than $85 \%$ of variation of stock index in each nation.

\subsection{Unit Root Test}

Cointegration requires the variables to be integrated of the same order. Hence, ADF and PP are carried out to verify their stationarity. Table 4 until Table 8 describes the result of ADF and PP unit root test for all countries. Both test unanimously classify selected variables as $I(1)$ 
that is, these variables are non-stationary at level but are stationary after first differencing. These are revealed by the significant values of the test statistic for the first difference data. Thus, now all the variables were integrated in the same order at $I(1)$, this study proceeds to test whether they have long run equilibrium relationship.

Table 3. Multiple Regression of macroeconomic variables in ASEAN

\begin{tabular}{llllll}
\hline \multicolumn{1}{c}{ Country } & Indonesia & Malaysia & Philippines & Singapore & Thailand \\
Variable & & & & & \\
\hline CPI & & -43.36 & 0.32 & -123.24 & 17.40 \\
EXR & -0.1844 & -492.87 & -0.76 & -2504.28 & -26.18 \\
GOLD & -0.7765 & -0.46 & & -1.08 & \\
IBOR & & -19.92 & 0.30 & 60.65 & -33.63 \\
IPI & & & & 13.09 & -2.85 \\
INT RES & & 0.0005 & $-3.73 \mathrm{E}-06$ & -0.01 & -0.0003 \\
M1 & & 0.004 & $2.35 \mathrm{E}-05$ & 0.01 & 1.42 \\
M2 & 0.001 & 0.0009 & & 0.01 & \\
OIL & 9.66 & 1.50 & 0.10 & 13.78 & \\
SILVER & 0.30 & 0.07 & & & 0.12 \\
$\mathrm{R}^{2}$ & 0.97 & 0.96 & 0.96 & 0.88 & 0.93 \\
Adj R ${ }^{2}$ & 0.97 & 0.95 & 0.96 & 0.87 & 0.93 \\
\hline
\end{tabular}

\subsection{Cointegration Test}

Before executing the Johansen-Juselius ( $\mathrm{JJ})$ test of cointegration, this study performs lag length selection test to determine the appropriate lag length. This study had chosen the AIC and FPE for selection of the order of VAR model. According to [28] AIC and FPE are better than the other criteria in the manners that they will minimize the chance of under estimation while maximizing the chance of recovering the true lag length. Besides, [29] also suggested to minimize Final Prediction Error (FPE) in order to determine the optimal lag structure.Both criteria suggested that the optimum lag length for Indonesia and Thailand are 3 while Malaysia, Philippines and Singapore are 2. 
Table 4: Result of unit root test of Indonesia

\begin{tabular}{lllll}
\hline & \multicolumn{2}{c}{ ADF } & \multicolumn{2}{c}{ PP } \\
\cline { 2 - 5 } Variables & Level & First Difference & Level & First Difference \\
\hline JCI & 2.43 & $-10.55^{* *}$ & 2.06 & $-10.62^{* *}$ \\
EXR & 0.40 & $-12.34 * *$ & 0.52 & $-12.42^{* *}$ \\
GOLD & 1.02 & $-10.63^{* *}$ & 0.82 & $-10.63^{* *}$ \\
M2 & 2.71 & $0.55^{* *}$ & 17.79 & $-12.05^{* *}$ \\
OIL & -0.53 & $-7.77^{* *}$ & -0.30 & $-7.84^{* *}$ \\
SILVER & -0.43 & $-10.17 * *$ & -0.35 & $-10.03^{* *}$ \\
\hline \multicolumn{5}{c}{$* *$ denotes significance at $5 \%$ level }
\end{tabular}

Table 5. Result of unit root test of Malaysia

\begin{tabular}{lclll}
\hline & \multicolumn{3}{c}{ ADF } & \multicolumn{2}{c}{ PP } \\
\cline { 2 - 5 } Variables & Level & First Difference & Level & First Difference \\
\hline KLCI & 1.51 & $-12.48^{* *}$ & 1.5 & $-12.55^{* *}$ \\
CPI & 4.38 & $-8.67 * *$ & 5.73 & $-8.79 * *$ \\
EXR & -1.35 & $-16.20^{* *}$ & -1.53 & $-18.95 * *$ \\
GOLD & 0.78 & $-11.79 * *$ & 0.88 & $-11.79 * *$ \\
IBOR & -0.77 & $-11.98^{* *}$ & -3.00 & $-12.07 * *$ \\
INT RES & 0.89 & $-10.29 * *$ & 0.89 & $-10.48^{* *}$ \\
M1 & 3.81 & $-0.55^{* *}$ & 9.75 & $-13.52^{* *}$ \\
M2 & 11.83 & $-0.52^{* *}$ & 10.56 & $-10.28^{* *}$ \\
OIL & -0.53 & $-8.74 * *$ & -0.30 & $-8.81 * *$ \\
SILVER & -0.50 & $-11.28^{* *}$ & -0.40 & $-11.143^{*}$ \\
\hline & & $* *$ & denotes significance at $5 \%$ level
\end{tabular}

Table 9 reported the results of Johansen-Juselius ( $\mathrm{JJ})$ test of cointegration for the five ASEAN countries. The table provides trace statistics, $\lambda_{\text {trace }}$ and maximum eigenvalue statistics, $\lambda_{\max }$. Close examination of the result indicates that $\lambda_{\text {trace }}$ and $\lambda_{\max }$ are significant at one cointegrating vector for Indonesia and Philippines, three cointegrating vectors for Malaysia, four cointegrating vectors for Singapore while two cointegrating vectors for Thailand. This signifies all the stock markets and their respective macroeconomic variables are moving 
together in the long run.

Table 6. Result of unit root test of Philippines

\begin{tabular}{lllll}
\hline & \multicolumn{3}{c}{ ADF } & \multicolumn{2}{c}{ PP } \\
\cline { 2 - 5 } Variables & Level & First Difference & Level & First Difference \\
\hline PSEi & 1.52 & $-17.12^{* *}$ & 2.09 & $-17.13^{* *}$ \\
CPI & 8.01 & $-4.00^{* *}$ & 11.06 & $-8.42^{* *}$ \\
EXR & 0.60 & $-12.09^{* *}$ & 0.68 & $-12.08^{* *}$ \\
IBOR & -1.58 & $-22.38^{* *}$ & -1.08 & $-29.40^{* *}$ \\
INT RES & 5.53 & $-4.80^{* *}$ & 4.49 & $-14.20^{* *}$ \\
OIL & 3.10 & $-0.55^{* *}$ & 9.16 & $-15.18^{* *}$ \\
M1 & -0.58 & $-9.53^{* *}$ & -0.33 & $-9.60^{* *}$ \\
IPI & 2.50 & $-4.76^{* *}$ & 2.64 & $-22.17 * *$ \\
\hline \multicolumn{5}{c}{$* *$ denotes significance at $5 \%$ level }
\end{tabular}

Table 7. Result of unit root test of Singapore

\begin{tabular}{lclll}
\hline & \multicolumn{3}{c}{ ADF } & \multicolumn{2}{c}{ PP } \\
\cline { 2 - 5 } Variables & Level & First Difference & Level & First Difference \\
\hline STI & 0.24 & $-14.24 * *$ & 0.13 & $-14.29 * *$ \\
CPI & 3.32 & $-5.55^{* *}$ & 4.73 & $-16.78^{* *}$ \\
EXR & -0.45 & $-13.99^{* *}$ & -0.47 & $-13.94 * *$ \\
GOLD & 0.78 & $-12.80^{* *}$ & 0.86 & $-12.80^{* *}$ \\
INT RES & 7.76 & $-4.47^{* *}$ & 7.01 & $-13.70^{* *}$ \\
IPI & 1.12 & $-21.40^{* *}$ & 0.82 & $-38.98^{* *}$ \\
M1 & 7.98 & $-4.94 * *$ & 7.46 & $-16.31 * *$ \\
M2 & 9.29 & $-4.96^{* *}$ & 7.59 & $-12.50^{* *}$ \\
OIL & -0.58 & $-9.53^{* *}$ & -0.33 & $-9.60^{* *}$ \\
IBOR & -1.37 & $-11.05^{* *}$ & -1.55 & $-13.97 * *$ \\
\hline & & $* *$ & denotes significance at $5 \%$ level
\end{tabular}


Table 8. Result of unit root test of Thailand

\begin{tabular}{lclll}
\hline & \multicolumn{3}{c}{ ADF } & \multicolumn{2}{c}{ PP } \\
\cline { 2 - 5 } Variables & Level & First Difference & Level & First Difference \\
\hline SETi & 1.83 & $-12.24 * *$ & 1.57 & $-12.35^{* *}$ \\
CPI & 3.38 & $-8.69^{* *}$ & 4.19 & $-8.77^{* *}$ \\
EXR & -0.52 & $-12.35^{* *}$ & -0.50 & $-12.37 * *$ \\
IBOR & -1.06 & $-5.56^{* *}$ & -1.75 & $-19.61^{* *}$ \\
INT RES & 1.56 & $-4.32^{* *}$ & 2.68 & $-12.24 * *$ \\
IPI & 0.94 & $-4.74^{* *}$ & 0.63 & $-29.60^{* *}$ \\
M1 & 2.62 & $-1.08^{* *}$ & 4.69 & $-16.20^{* *}$ \\
SILVER & -0.47 & $-10.90^{* *}$ & -0.37 & $-10.76^{* *}$ \\
\hline
\end{tabular}

** denotes significance at $5 \%$ level

Table 9.JJ Cointegration Test for five ASEAN

\begin{tabular}{lccc}
\hline \multicolumn{1}{c}{ Country } & $H_{a}$ & Trace Statistic, & Max-Eigen Statistic, \\
& (No. of CE(s)) & $\lambda_{\text {trace }}$ & $\lambda_{\max }$ \\
\hline Indonesia & At least 1 & $102.18^{* *}$ & $42.96^{* *}$ \\
Philippines & At least 1 & $165.64 * *$ & 46.01 \\
Thailand & At most 1 & $138.91^{* *}$ & $48.01 * *$ \\
Malaysia & At most 2 & $174.11^{* *}$ & $56.39^{* *}$ \\
Singapore & At most 3 & $147.16^{* *}$ & 42.45 \\
\hline \multicolumn{4}{c}{} \\
\hline
\end{tabular}

It appears that Table 9 produced contradict results for $\lambda_{\text {trace }}$ and $\lambda_{\max }$. [30] suggested that trace test tends to have more distorted sizes whereas their power is in some situations superior to that of the maximum eigenvalue test. Thus, the selection for the number of cointegrating vectors is based on $\lambda_{\text {trace. }}$ As all the countries indicate significance of JJ test, VEC model will be used to model the relationship. Full results for the VEC model will be provided upon request from the authors. The Granger Causality test will be presented in the next section.

\subsection{Granger Causality Test}

The short run impact of the macroeconomic variable behavior on the stock indices was examined using the Granger causality test under the framework of an unrestricted stationary VAR or VEC model. Thus, the following Table 10 to Table 14 will explain deeply about 
interesting findings in this test. Now, bear in mind that there are only two directions of Granger causes - unidirectional or bidirectional causality which will be focused in this study.Some or all significant results will be displayed in each table.

Table 10. Granger Causality test of Indonesia

\begin{tabular}{lll}
\hline Null Hypothesis & $\chi^{2}$ statistic & Casual Inference \\
\hline EXR does not Granger Cause JCI & $22.10^{* *}$ & Causality \\
SILVER does not Granger Cause JCI & $7.62^{* *}$ & Causality \\
GOLD does not Granger Cause EXR & $9.98^{* *}$ & Causality \\
OIL does not Granger Cause EXR & $17.19^{* *}$ & Causality \\
EXR does not Granger Cause M2 & $23.61 * *$ & Causality \\
\hline
\end{tabular}

** denotes significance at $5 \%$ level

Table 10 above presents the chi square test statistics of Granger Causality test for Indonesia. After examining closely, JCI do not Granger cause all the macroeconomic variables, however EXR and Silver Ganger cause JCI. This suggests that any depreciation or appreciation of Rupiah will result the JCI to fall or to jump up. The result also in line with the Asian Financial Crisis in 1997 where most of the Asian stock market plunged down when their currencies depreciated. Besides, OIL and Gold Granger causes EXR. An increase in oil prices usually seen as inflation by policy makers and central banks responds to inflation pressures by raising the interest rates. This in turn will increase the currency deposits as it is more attractive to save money in banks. Thus, the exchange rates appreciate. We also found that EXR Granger causes M2.

Referring to Table 11, the table provides information about the Granger causality test in the context of Malaysia. In contrast to the previous result for Indonesia, none of the macroeconomic variables Granger cause KLCI. However, KLCI Granger causes IBOR, INT RES, M1 and M2. This means that fluctuation of KLCI is an indication about the performance of Interbank offer rate, International reserves and Money supply. While as an oil exporter country, there is a bidirectional Granger cause between CPI and OIL in Malaysia. Typically, any increase of oil price in Malaysia will lead to the increasing price level of goods. Thus, producers and entrepreneurs always use this reason to raise the price level as they are facing high production cost. In addition, GOLD and SILVER are Granger cause EXR. Typically silver and gold rises together in a bullish market because investors always choose both of the 
precious metals as a hedge of inflation. Thus, according to [31], any increase in the price of silver will cause the depreciation of the greenback against major currencies as traders sell US dollar and buy silver. From here we can see that the depreciation on greenback will increase the exchange rate of Ringgit Malaysia against the US dollar. Hence, this may explain our findings that precious metal price Granger causes exchange rates in Malaysia.

Table 11. Granger Causality test of Malaysia

\begin{tabular}{lll}
\hline Null Hypothesis & $\chi^{2}$ statistic & Casual Inference \\
\hline OIL does not Granger Cause CPI & $3.75^{* *}$ & Causality \\
CPI does not Granger Cause OIL & $6.95^{* *}$ & Causality \\
GOLD does not Granger Cause EXR & $3.66^{* *}$ & Causality \\
SILVER does not Granger Cause EXR & $7.78^{* *}$ & Causality \\
M1 does not Granger Cause GOLD & $3.97 * *$ & Causality \\
KLCI does not Granger Cause IBOR & $6.00^{* *}$ & Causality \\
KLCI does not Granger Cause INT RES & $6.16^{* *}$ & Causality \\
KLCI does not Granger Cause M1 & $4.37 * *$ & Causality \\
KLCI does not Granger Cause M2 & $4.97 * *$ & Causality \\
\hline
\end{tabular}

As seen in Table 12, similar to Malaysia all the macroeconomic variables do not Granger cause the Philippines Stock Exchange Index (PSEi). It is interesting to find that as an oil importer country, oil prices Granger cause EXR and IPI. While IPI Granger cause CPI. This finding indicates rising in oil prices will cause an increase of manufacturing cost at production level. Manufacturers had to transfer the costs to customers as they have to bear high production and transportation costs. This in turn will result rising in price level or inflation. Further interesting findings in Table 11, it shows that the money supply, M1 Granger causes CPI and also vice versa. In short, an increase in money supply will increase the consumer price index. Increasing of money supply means that there is an expansion of monetary policy in the Philippines.

According to [32], a permanent increase in a country's money supply causes a proportional long-run depreciation of its currency against foreign currencies, ceteris paribus. In the context of the Philippines, if the money supply increase the Peso dollar will be weakened in the long run as compared to greenback since we use the US dollar as foreign currency in this study. Thus, Filipinos will need more Pesos as the price level is rising. This is because in the short 
run, a change in money supply has an expansionary effect on the economy which raising the total demand for final good and services. Thus, total demand for goods will increase the raw material prices such as petroleum and metals used in productions of final goods. They are sold in markets where prices adjust sharply even in the short run. Hence, an increase in money supply raises the production costs in material-using industries. Finally, producers will raise their product prices to cover the higher production costs.

Table 12. Granger Causality test of Philippines

\begin{tabular}{lll}
\hline Null Hypothesis & $\chi^{2}$ statistic & Casual Inference \\
\hline IPI does not Granger Cause CPI & $4.98^{* *}$ & Causality \\
M1 does not Granger Cause CPI & $39.79^{* *}$ & Causality \\
PSEi does not Granger Cause EXR & $14.04^{* *}$ & Causality \\
OIL does not Granger Cause EXR & $4.23^{* *}$ & Causality \\
PSEi does not Granger Cause INT RES & $7.92^{* *}$ & Causality \\
M1 does not Granger Cause IPI & $31.59^{* *}$ & Causality \\
OIL does not Granger Cause IPI & $6.12^{* *}$ & Causality \\
CPI does not Granger Cause M1 & $4.22^{* *}$ & Causality \\
INT RES does not Granger Cause OIL & $3.67^{* *}$ & Causality \\
\hline
\end{tabular}

** denotes significance at $5 \%$ level

In Singapore (Table 13), there is no Granger causality found between the macroeconomic variables and STI. M2 is found to be Granger causes oil price and vice versa, since the chi square coefficients of 7.96 and 5.23 are significant at the $5 \%$ level respectively. As we discussed earlier in the context of the Philippines, there is no doubt that the expansion of monetary policy will raise the oil price in Singapore in the short run. Besides, our findings also show that M1 Granger causes IPI. Again, this result is in line with [19] findings for Thailand perspective. The expansion of money supply will increase the industrial production due triggers in demand as the producer compete to meet this demand. However, this may not exactly fit the theory as manufacturing industries in Singapore is not too active due to limited resources and space. Another finding depicted in the table above are STI, GOLD and INT RES Granger causes M2, while oil price Granger causes CPI and M2. 
Table 13. Granger Causality test of Singapore

\begin{tabular}{lll}
\hline Null Hypothesis & $\chi^{2}$ statistic & Casual Inference \\
\hline OIL does not Granger Cause CPI & $4.40^{* *}$ & Causality \\
M2 does not Granger Cause OIL & $7.96^{* *}$ & Causality \\
OIL does not Granger Cause M2 & $5.23^{* *}$ & Causality \\
M1 does not Granger Cause IPI & $14.40^{* *}$ & Causality \\
STI does not Granger Cause M2 & $4.89^{* *}$ & Causality \\
GOLD does not Granger Cause M2 & $4.23^{* *}$ & Causality \\
INT RES does not Granger Cause M2 & $9.24^{* *}$ & Causality \\
OIL does not Granger Cause CPI & $4.40^{* *}$ & Causality \\
OIL does not Granger Cause M2 & $5.23 * *$ & Causality \\
\hline & $* *$ denotes significance at $5 \%$ level &
\end{tabular}

Lastly Table 14 reported that the SETi Granger cause EXR and IPI while IBOR, IPI and M1 Ganger cause SETi. This finding indicates that IBOR, IPI and M1 are some of the forces that driven the fluctuation of SET. Meanwhile SETialso causes uncertainty in EXR and IPI. Probably any news regarding SETi will affect the Thailand Bath performance.

Table 14. Granger Causality test of Thailand

\begin{tabular}{lll}
\hline Null Hypothesis & $\chi^{2}$ statistic & Casual Inference \\
\hline SETidoes not Granger Cause EXR & $5.70^{* *}$ & Causality \\
SETi does not Granger Cause IPI & $7.90^{* *}$ & Causality \\
IBOR does not Granger Cause SETi & $6.36^{* *}$ & Causality \\
IPI does not Granger Cause SETi & $5.71^{* *}$ & Causality \\
M1 does not Granger Cause SETi & $8.69^{* *}$ & Causality \\
\hline
\end{tabular}

** denotes significance at $5 \%$ level

\subsection{Forecast Error Variance Decomposition (FEVD)}

In this section, we will further discuss interesting findings that appear in each country. This method is employed to further examine the dynamic interaction between stock indices and selected macroeconomic variablesbeyond the sampling period by using FEVD. The results show how they react to their own shocks and shocks in other variables. The advantage of this approach is that the data are allowed to decide whether the shocks are permanent or temporary. Table 15 to Table 19 show the dynamic interaction between all the stock markets and their selected macroeconomic variables. It seems that after 6 months the fluctuation of all the stock markets are caused by their own shocks. Furthermore, after a year, PSEi, SETi and JCI still responds aptly to their own innovations. While for Malaysia KLCI, after a year, we noted that 
a shock from oil prices have the most contributions to fluctuation of KLCI which is about $11 \%$. Therefore, it is advised that investors should monitor closely oil prices before doing any trading.

Table 15. FEVD Results for Indonesia

\begin{tabular}{ccccccc}
\hline Month & JCI & EXR & GOLD & M2 & OIL & SILVER \\
\hline 1 & 100 & 0.00 & 0.00 & 0.00 & 0.00 & 0.00 \\
3 & 95.84 & 1.30 & 0.99 & 0.10 & 0.15 & 1.59 \\
6 & 92.13 & 0.84 & 4.70 & 0.08 & 0.25 & 1.97 \\
9 & 87.17 & 1.53 & 6.70 & 0.09 & 1.32 & 3.16 \\
12 & 82.98 & 2.30 & 7.57 & 0.10 & 2.98 & 4.03 \\
\hline
\end{tabular}

Table 16. FEVD Results for Malaysia

\begin{tabular}{ccccccccccc}
\hline Month & KLCI & CPI & EXR & GOLD & IBOR & INT & M1 & M2 & OIL & SILVER \\
& & & & & & RES & & & & \\
\hline 1 & 100 & 0.00 & 0.00 & 0.00 & 0.00 & 0.00 & 0.00 & 0.00 & 0.00 & 0.00 \\
3 & 94.91 & 0.14 & 0.40 & 0.004 & 0.78 & 0.99 & 0.43 & 1.04 & 1.25 & 0.02 \\
6 & 87.10 & 0.10 & 0.74 & 0.04 & 1.37 & 2.28 & 0.59 & 2.11 & 5.30 & 0.32 \\
9 & 80.86 & 0.09 & 1.09 & 0.14 & 1.59 & 3.44 & 0.47 & 2.62 & 8.92 & 0.74 \\
12 & 76.93 & 0.085 & 1.39 & 0.30 & 1.54 & 4.42 & 0.34 & 2.76 & 11.12 & 1.08 \\
\hline
\end{tabular}

Table 17. FEVD Results for Philippines

\begin{tabular}{ccccccccc}
\hline Month & PSEi & CPI & EXR & IBOR & $\begin{array}{c}\text { INT } \\
\text { RES }\end{array}$ & IPI & M1 & OIL \\
\hline 1 & 100 & 0.00 & 0.00 & 0.00 & 0.00 & 0.00 & 0.00 & 0.00 \\
3 & 97.83 & 1.08 & 0.0008 & 0.18 & 0.15 & 0.15 & 0.55 & 0.02 \\
6 & 96.84 & 1.74 & 0.001 & 0.14 & 0. & 0.41 & 0.60 & 0.04 \\
9 & 96.39 & 2.02 & 0.0007 & 0.12 & 0.22 & 0.54 & 0.63 & 0.05 \\
12 & 96.14 & 2.16 & 0.0005 & 0.11 & 0.23 & 0.61 & 0.66 & 0.05 \\
\hline
\end{tabular}

Table 18. FEVD Results for Singapore

\begin{tabular}{ccccccccccc}
\hline Month & \multirow{2}{*}{ STI } & \multirow{2}{*}{ CPI } & EXR & GOLD & IBOR & $\begin{array}{c}\text { INT } \\
\text { RES }\end{array}$ & IPI & M1 & M2 & OIL \\
\hline 1 & 100 & 0.00 & 0.00 & 0.00 & 0.00 & 0.00 & 0.00 & 0.00 & 0.00 & 0.00 \\
3 & 95.77 & 1.18 & 0.23 & 1.36 & 0.004 & 0.20 & 0.69 & 0.37 & 0.06 & 0.09 \\
6 & 88.86 & 2.08 & 2.06 & 2.42 & 0.02 & 0.56 & 1.61 & 0.94 & 0.11 & 1.28 \\
9 & 81.76 & 2.74 & 4.26 & 2.97 & 0.07 & 0.90 & 2.11 & 1.58 & 0.11 & 3.46 \\
12 & 76.35 & 3.18 & 5.93 & 3.16 & 0.20 & 1.11 & 2.38 & 2.07 & 0.11 & 5.47 \\
\hline
\end{tabular}

Table 19. FEVD Results for Thailand 


\begin{tabular}{ccccccccc}
\hline Month & SETi & CPI & EXR & IBOR & $\begin{array}{l}\text { INT } \\
\text { RES }\end{array}$ & IPI & M1 & SILVER \\
\hline 1 & 100 & 0.00 & 0.00 & 0.00 & 0.00 & 0.00 & 0.00 & 0.00 \\
3 & 95.71 & 0.11 & 0.38 & 0.35 & 1.22 & 0.05 & 1.72 & 0.43 \\
6 & 93.70 & 0.08 & 1.18 & 0.55 & 1.03 & 0.24 & 2.82 & 0.35 \\
9 & 91.21 & 0.35 & 1.78 & 0.86 & 0.75 & 0.60 & 4.16 & 0.25 \\
12 & 89.77 & 0.60 & 2.03 & 1.06 & 0.56 & 0.83 & 4.89 & 0.21 \\
\hline
\end{tabular}

\section{CONCLUSIONS AND RECOMMENDATIONS}

In short, this study investigates the factors that affect the stock market from the macroeconomic perspective in selected ASEAN countries. Typically, a nature of resilient economy influence by economic policies and mechanisms that drive the soar of stock markets. A consistent growth of stock markets is essential because it determines the prosperity and wealth of nations. As people are prosperous they tend to consume more, hence producing more outputs and cash flow increases; these factors have the tendency to the growth of GDP. Thus, by using Johansen - Juseliuscointegration analysis and monthly time-series data, this study has captured that macroeconomic variables have a long run equilibrium effect on ASEAN stock indices.

Moreover, the Granger causality test had shown that some of the selected macroeconomic variables have Granger causes Kuala Lumpur Composite Index (KLCI), Philippines Stock Exchange Index (PSE) and FTSE Straits Time Index (STI). While, Jakarta Composite Index (JCI) Granger causes some of the selected macroeconomic variables. Surprisingly FTSE Straits Time Index (STI) Granger cause on both ways, either from STI or from macroeconomic variables. In addition,forecast error variance decomposition uncover that the shock from selected macroeconomic variables for each country have only minor effect on their stock market.

Previously, we had seen and compared the results of this study to the other studies. We believe that there are a lot of improvement and extension of ideas can be proposed in the future. Perhaps, future research may extend this study by including all ASEAN countries and seek for dynamic relationship among them. Besides, future study may also employ Principal Component Analysis (PCA) technique instead of multiple regression for selection of macroeconomic variables. Further, the study about the dynamic relationship between ASEAN 
stock indices also may be an interesting prospective to analyze the behavior of ASEAN stock markets.

\section{ACKNOWLEDGEMENTS}

We would like to acknowledge support for this project from Universiti Sains Malaysia (USM Short-term grant 304/PMATHS/6313068).

\section{REFERENCES}

[1] De Gregorio J, Guidotti P E. World Dev. 1995, 23 (3), 433-448, doi: 10.1016/0305-750X(94)00132-I.

[2] Friedman B. Principles and techniques of applied mathematics. New York: Wiley, 1956, pp. 280.

[3] Sharpe W F J. Finance. 1964, 19 (3), 425-442, doi: 10.1111/j.1540-6261.1964.tb02865.x.

[4] Ross S A. J Econ. Theory. 1976, 13 (3), 341-360, doi: 10.1016/0022-0531(76)90046-6.

[5] Garcia V F, Liu L. Macroeconomic determinants of stock market development. J. Appl. Econ., 1999, 2(1):29-59

[6] Basci E S, Karaca S S. The determinants of stock market index: VAR approach to Turkish stock market. Int. J. Econ. Financ., 2013, 3(1):163-171

[7] Chen N F, Roll R, and Ross S A. Economic forces and the stock market revisited. J. Bus., 1986, 59(3):383-403

[8] Granger C W J. Developments in the study of cointegrated economic variables. Oxf. Bull. Econ. Stat., 1986, 48(3):213-228

[9] Johansen S. Estimation and hypothesis testing of cointegration vectors in gaussian vector autoregressive models. Econ., 1991,59(6):1551-1580

[10] Mukherjee T, Naka A. Dynamic relations between macroeconomic variables and the Japanese stock market: An application of a vector error correction model. J. Financ. Res., $1995,18: 223-237$

[11] Kwon C S, Shin T S. Cointegration and causality between macroeconomic variables and stock market returns. Glob. Fin. J., 1999, 10(1):71-81 
[12] Garcia V F, Liu L. Macroeconomic determinants of stock market development. J. Appl. Econ., 1999, 2(1):29-59

[13] Maysami R C, Koh T S. A vector error correction model of the Singapore stock market. Int. Rev. Econ. Financ., 2000, 9(1):79-96

[14] Wongbangpo P, Sharma S C. Stock market and macroeconomic fundamental dynamic interactions: ASEAN-5 countries. J. Asia. Econ., 2002, 13, 27-51

[15] Nishat M, Shaheen R. Macroeconomic factors and Pakistani equity market. The Pakistan Dev. Rev., 2004, 43(4):619-637

[16] Al-Sharkas A. The dynamic relationship between macroeconomic factors and the Jordanian stock market. Int. J. Appl. Econom. Quant. Stud., 2004, 1(1):97-114

[17] Rahman A, Mohd Sidek N Z, and Tafri F H, Macroecnomic determinants of Malaysian stock market. African J. Bus. Manag., 2009, 3(3):95-106

[18] Hsing Y. Impacts of macroeconomic factors on the stock market in Estonia. American Res. Institute for Policy Dev., 2014, 2(2):23-31

[19] Forson J A, Janrattanagul J. Selected macroeconomic variables and stock market movements: Empirical evidence from Thailand. Contemporary Econ, 2014, 8(2):154

[20] Sukruoglu D, TemelNalin H. The macroeconomic determinants of stock market development in selected European countries: Dynamic panel data analysis. Int. J. Econ. Financ., 2014, 6(3):64-71

[21] Khan R E A, Ali R. Causality analysis of volatility in exchange rate and stock market prices: A case study of Pakistan. Asian Econ. and Financ. Rev., 2015, 5(5):805-815

[22] Niyazbekova S U, Grekov I E, and Blokhina T K. Econ. Region. 2016, 12 (4):1263-1273 [23] Ho S Y, Iyke B N. Studies in Economics and Finance, 2017, 34 (1):143-164

[24] Alias L. Introductory business forecasting a practical approach. Selangor:UniversitiTeknologi MARA Press, 2014

[25] KasriR A, Kassim S. Empirical determinants of saving in the Islamic banks: Evidence from Indonesia. The Journal of King Abdulaziz University: Islamic Econ., 2009, 22(2):181-201

[26] Masih A M M, Masih R. Bivariate and multivariate tests of money-price causality: Robust evidence from a small developing country. J. Int. Dev., 1997, 9, 803-825 
[27] Factbox. Thailand's flood crisis and the economy, 2011

[28] Liew V K. Which lag length selection criteria should we employ? Econ. Bulletin, 2004, $3(33): 1-9$

[29] Tan H B, Hooy C W. Understanding the behavior of the Malaysian stock market Serdang: Universiti Putra Malaysia Press, 2005

[30] Lutkepohl H, Saikkonen P, and Trenkler C. Maximum eigenvalue versus trace tests for the cointegrating rank of a VAR process. The Econ. J., 2001, 4(2):287-310

[31] Bhar R, Malliaris A G. Oil prices and the impact of the financial crisis of 2007-2009. Energy Econ., 2001, 33, 1049 -1054

[32] Krugman P R, Obstfeld M. International economics: Theory and policy. Indiana: Addison-Wesley, 2003

\section{How to cite this article:}

Ismail M T, Che Rose F Z, Rosmanjawati A R. The dynamic relationship between selected asean stock markets and their macroeconomic variables.J. Fundam. Appl. Sci., 2017, 9(5S), 868-897. 